\title{
CONSTRUCCIÓN DE TRADICIONES HISTORIOGRÁFICAS EN PSICOLOGÍA Y PSICOANÁLISIS
}

\begin{abstract}
RESUMO. La presente investigación revisa dos tradiciones historiográficas en psicología; la tradición historiográfica anglo sajona, introducida por Boring en Estados Unidos y la tradición historiográfica psicoanalítica, introducido por Jones en Inglaterra. Se propone el nombre de tradición historiográfica para describir las operaciones y reconstrucciones historiográficas que tamizan el conocimiento de la historia de la psicología y del psicoanálisis. El trabajo analiza los presupuestos de ambas tradiciones desde el campo de los estudios históricos y algunas concepciones de la historiografía, en particular de la obra de Hobsbawn y José Luis Romero, tanto como el significado mítico de ambas tradiciones.
\end{abstract}

Palavras-chave: tradición historiográfica, psicología, psicoanálisis.

\section{THE MAKING OF HISTORIOGRAPHIC TRADITIONS IN PSYCHOLOGY AND PSYCHOANALYSIS}

\begin{abstract}
The present paper reviews two historiographic traditions within psychological field: the Anglo-Saxon historiographic tradition, introduced by Boring in the United States, and the psychoanalytical historiographic tradition, introduced by Jones in England. The name historiographic tradition is proposed to describe the historiographic operations and reconstructions that sift the knowledge of the history of psychology and psychoanalysis. The research points out the historiographic bases of both traditions from the point of view of historical studies. Some concepts from the historians Eric Hobsbawm and Jose Luis Romero are analyzed as well as the mythical significance of both traditions.
\end{abstract}

Key words: Historiographic tradition, psychology, psychoanalysis.

\begin{abstract}
"We were offered an account of Wundt's psychology that turned out to be more myth than fact, more legend than truth. For 100 years after the formal founding of psychology, teachers and textbooks about the history of psychology (including earlier editions of this text) compounded and reinforeced the error. This experience provides another example of how then changing data of history can influence our understanding of past events"
\end{abstract}

(Schultz \& Schultz, 1996, p. 70).
Hace más de una década, en el marco de la tradicional Convención Anual de la American Psychological Association, uno de los más destacados historiadores de la psicología contemporáneas, Danziger (1993) planteaba cierto divorcio entre el campo de la historia de la ciencia y el de la ciencia. La disciplina que en su opinión mejor ilustraba este divorcio era la física. En efecto, a la física contemporánea no le interesa mayormente la investigación sobre las teorías de Galileo y mucho menos sobre la física aristotélica. Esas temáticas quedan claramente en manos del historiador de la

* Profesor Titular Efectivo de Historia de la Psicología de la Universidad Nacional de San Luis. Licenciado en Psicología en la Universidad del Salvador, Argentina y Doctor en Historia en la Universidad de Buenos Aires. Investigador del Consejo Nacional de Investigaciones Científicas y Técnicas (CONICET), institución donde en el 2005 Coordinó la Comisión Asesora en Filosofía, Psicología y Ciencias de la Educación. Es Docente-Investigador Categoría 1 del Programa de Incentivos a la Investigación (Consejo Interuniversitario Nacional - Secretaría de Políticas Universitarias de la Nación). Fue el Primer Coordinador de la "Task Force on History of Psychology" de la Interamerican Society. 
ciencia el cual, a su vez, mantiene un distanciamiento marcado con el campo de la física. Distinto, señalaba Danziger, era el caso de la economía o la sociología. En estas disciplinas, el estudio de Ricardo o Smith o el de Durkheim y Weber formaban parte de la investigación contemporánea en esas disciplinas (Danziger, 1993, 1994).

Mostrando la diferencia entre esas disciplinas, Danziger (1993) se permitía interrogarse sobre cuál sería el camino que tomaría la historia de la psicología: ¿el de la física o el de la economía o las ciencias sociales en general? El problema que planteaba Danziger podría también derivar en el siguiente interrogante, que me atrevería a formular avanzando en las ideas de Danziger. ¿Estaremos los historiadores de la psicología condenados al aislamiento de nuestro campo disciplinar como en el caso de la física?

Desde ya, existen variadas respuestas a ese planteo. En una dirección si se quiere optimista, se puede constatar rápidamente que, desde un punto de vista cuantitativo, la história de la psicología viene ocupando un lugar destacado en el campo de la psicología. En efecto, se podría verificar el espacio que ocupa en publicaciones periódicas de psicología en general; la edición de libros dedicados a la temática, la existencia de proyectos y programas de investigación sobre el tema como así también la existencia de cursos de grado y de posgrado en diversas universidades. Inclusive, la existencia de cursos de historia de la psicología se ha convertido casi en una exigencia curricular en los últimos años en la Argentina, Brasil y en otros muchos países.

Pero no es sólo un fenómeno regional. En el ámbito internacional, podrían citarse dos testimonios en la misma línea. En primer lugar, el relevamiento que Samelson (1999) realizara hacia el cambio de siglo sobre el campo de la historia de la psicología, el cual evidencia un florecimiento destacado si se lo compara con el panorama desolador de los años 60, cuando recién empezaba a profesionalizarse la historia de la psicología. En segundo lugar, la edición todavía en prensa a cargo de Adrian Brock del primer volumen que analiza la historia de la psicología en un contexto claramente internacional evidenciando que ese crecimiento de la historia de la psicología puede experimentarse en sociedades tan disímiles como Argentina, India, China o Turquía (Brock, en prensa).

Sin embargo, también podrían encontrarse razonamientos en una dirección divergente. No obstante tal florecimiento y de la constitución de un campo de especialización en la historia de la psicología, todavía perduran los obituarios, homenajes e historias militantes que nos acercan al antiguo modelo de la historia celebratoria o legitimante o whig. Y en relación con la existencia de cursos de grado y de posgrado sobre historia de la psicología, característica que Samelson también observara en Estados Unidos y Canadá, ¿no será cierto que finalmente, como afirmaba Danziger (1994), dichos cursos están más del lado de las relaciones públicas que de las verdaderas exigencias académicas de formación?

Por otro lado, aún cuando lográramos que esos homenajes y cursos estuvieron rodeados de un antídoto fuertemente antilegitimante, aun cuando nos esforzáramos y tuviéramos éxito en incorporar una mirada crítica en todas esas actividades, ¿tenemos alguna seguridad de cómo es recibida entre nuestros estudiantes y entre nuestros colegas las pretensiones críticas de nuestras investigaciones históricas y de nuestra enseñanza de la historia? Este interrogante es el que en el fondo quisiera contribuir a desentrañar en este trabajo. Para ello, me parece pertinente partir de dos estudios empíricos.

El primero de ellos, que ya ha cumplido una década, es un estudio de Brock (1993) sobre la manera en que ha impactado en libros de textos de historia de la psicología, la nueva interpretación sobre Wundt que ha caracterizado a la historiografía de la psicología de las últimas décadas. Brock advierte que en realidad, aun cuando la nueva bibliografía haya sido casi siempre citada e incluida, los hallazgos más interesantes de esa nueva interpretación terminan por ser desconocidos o desacreditados. En su consideración, las interpretaciones clásicas sobre Wundt ya han adquirido un valor mítico y los mitos resultan esenciales a la función socializadora de los manuales de texto.

El segundo estudio aborda una temática parecida. Zehr (2000) examinó las maneras como enfocaban la obra de Titchener y Wundt los manuales introductorios a la psicología publicados en la década de 1990 en Estados Unidos, comparándolas con los publicados en la década de 1970. Lo interesante del estudio de Zehr fue el recurso metodológico que utilizó. En primer lugar seleccionó 20 manuales publicados entre 1994 y 1998 y los comparó con 15 manuales publicados entre 1973 y 1979. En segundo lugar, transcribió por separado todos los fragmentos de esos libros relacionados con Wundt y Titchener. Posteriormente les pidió a dos evaluadores independientes, ajenos al 
campo de la historia de la psicología que leyeran esos párrafos y que caracterizaran en rótulos las características de los sistemas de Wundt y de Titchener. Por último, les solicitó a esos mismos evaluadores que establecieran la diferencia o similitud entre los sistemas de Wundt y Titchener, en una Escala Lickert de 5 puntos, donde 1 expresaba la mayor diferencia y 5 la mayor similitud.

El resultado arrojó una media de 4,55. Es decir, a partir de los fragmentos de los textos, dos lectores sin formación en el campo de la historia de la psicología, situación habitual para quienes recién se inician en el estudio de una disciplina, podían deducir que entre los sistemas de Wundt y de Titchener, las similitudes eran enormes, no obstante que esa supuesta similitud ha sido uno de los tópicos que precisamente más ha cuestionado y re-examinado la historiografía crítica desde 1975 (Danziger, 1979a; Leahey, 1981).

Me parece que los dos ejemplos ponen de manifiesto que mientras la historia de la psicología marcha por un determinado camino, la psicología general, expresada en textos de carácter introductorio, o lo que bien podríamos denominar, la cultura psi, marcha por un camino paralelo.

No obstante, sería incorrecta deducir de ello que la cultura psi carezca de apreciación histórica, tanto en general, como de su disciplina en particular. En ese sentido, la segunda cuestión que quisiera plantear en este trabajo, se relaciona con el tipo de apreciación histórica que parece predominar en los medios psicológicos y que, tal como puede apreciarse en los estudios de Brock (1993) y de Zehr (2000), se encuentra tan distantes de los estudios de los historiadores profesionales de la disciplina.

Empezaré entonces por definir ese tipo de apreciación histórica con el nombre de tradiciones historiográficas. $\mathrm{Si}$ bien existen numerosas tradiciones historiográficas, me referiré especialmente a dos.

Una de ellas, que en verdad ya sido bastante analizada aunque no definida de esta manera, es la tradición historiográfica anglosajona. Esta tradición fue esbozada por Titchener (1921) en ocasión de la necrológica publicada a la muerte de Wundt, pero adquirió carta de ciudadanía a partir de la Historia de la Psicología experimental de Boring, cuya primera edición data de 1929 y la segunda, ampliamente difundida de 1950.

La otra, casi desconocida en el mundo anglosajón, es la tradición historiográfica psicoanalítica, de fuerte influencia en los países del Mercosur, especialmente en Argentina y Uruguay y en menor medida en Brasil, aunque también dentro de los circuitos psicoanalíticos en general. Esta tradición fue esbozada inicialmente por Freud en su Historia del movimiento psicoanalítico, pero adquirió carta de ciudadanía con Vida y Obra de Sigmund Freud de Ernest Jones, publicada originalmente entre 1953 y 1957.

Propongo la denominación de tradiciones historiográficas, para designar las diferentes reconstrucciones históricas de la disciplina fuertemente sesgada por un conjunto de operaciones intelectuales destinadas a justificar y legitimar posiciones contemporáneas recurriendo a la historia. Tales operaciones y reconstrucciones conllevan una impronta fuertemente whig y celebratoria, aun cuando el análisis de fuentes documentales pueda ser minucioso. El objetivo estratégico de estas tradiciones es el de tamizar el conocimiento de la historia de la psicología y del psicoanálisis como parte de una estrategia propiamente institucional y política aun más general, comprometida con las posiciones institucionales predominantes en la psicología anglosajona, en el primer caso, y del psicoanálisis, en el segundo.

Esta estrategia y este compromiso, me parece, explican bien los resultados de los estudios de Brock (1993) y de Zehr (2000). En verdad, para las tradiciones historiográficas, el conocimiento histórico no es verdaderamente relevante, sino únicamente un medio para la socialización de los integrantes de un determinado campo profesional y/o académico y para fortalecer una determinada identidad de grupo. En ese sentido, si las nuevas investigaciones historiográficas pudieran llegar a poner en tela de juicio los conocimientos históricos de determinadas tradiciones, nuevas operaciones intelectuales, propias de los mecanismos de perpetuación de esas mismas tradiciones historiográficas, estarían encargadas de su omisión o descalificación.

Por tal razón, las dos tradiciones historiográficas, cada una a su manera, enfatizan un acontecimiento mítico originario junto a una principal figura mítica, al mismo tiempo que un sólo método por el cual surgió la psicología, omitiendo señalar la pluralidad de problemas y de abordajes que caracterizaron el surgimiento de la psicología en el último cuarto del siglo XIX.

Desde ya, existen diferencias notorias entre cada una de esas tradiciones historiográficas. Aquí nos interesará remarcar los rasgos en común, para lo cual recurriremos al análisis de pensadores del campo historiográfico. 
En su obra Futuro pasado, Koselleck (1993) comentaba una de las pinturas que en 1528, el duque Guillermo IV de Baviera había encargado sobre temas históricos. La más famosa de aquellas pinturas, en opinión de Koselleck, es una realizada por Albrecht Altdörfer que representa la batalla de Isso en el año 333, en la cual Alejandro derrotaba a los persas, inaugurando el período helenista.

Hay unos cuantos elementos anacrónicos de esa obra pictórica que Koselleck (1993) destaca. En primer lugar, el cuadro representa varios miles de combatientes cuyo número aparece en las banderas del ejército al que pertenecen. En segundo lugar, Alejandro se parece más al último caballero Maximiliano mientras los persas, "desde los pies al turbante", se asemejaban a los turcos que asediaban infructuosamente a Viena en el mismo año 1529 en que se realizó el cuadro. Es decir, la obra magnífica de Albrecht Altdörfer, aun cuando explícitamente se refería a un suceso histórico de varios siglos atrás, implícitamente, también representaba acontecimientos contemporáneos. La apelación a la historia, entonces, interesaba en tanto esa historia podía ser de utilidad para la resignificación de acontecimientos contemporáneos.

Las tradiciones historiográficas que nos interesan en este trabajo responden a un análogo anacronismo. En cierto sentido, cuando Boring, en 1929, escribe sobre Wundt, el retrato de Wundt que reconstruye se parece más a Titchener e inclusive al del propio Boring, cuyo modelo de psicología languidecía frente a los embates de las armas conductistas y, sobre todo, frente al avance de la caballería de la psicología aplicada. Y el retrato de Freud de Jones resulta difícil de separar del retrato de cualquier psicoanalista perteneciente a la International Psychoanalytical Association, entre ellos, por supuesto Jones, en las difíciles batallas que debían librar los psicoanalistas luego de la diáspora, lejos del mundo vienés de habla alemana que los había cobijado inicialmente, frente a los embates de las armas de otros modelos de psicología más contrastables y sobre todo, frente a los embates de otros psicoanalistas también formados por Freud y que no adhirieron a los rígidos sistemas establecidos por la IPA de aquellos años.

No he recurrido por azar a las imágenes bélicas. El último Maximiliano que se confundía con Alejandro, Boring (1993), fundiéndose con Titchener y Wundt o Jones identificándose con Sigmund Freud o con su hija Anna para encarnar las políticas de la International Psychoanalytical Association, son todos testimonios de un mismo objetivo estratégico: el recurso a la historia como parte de batallas institucionales contemporáneas.

Desde ya, no se pretende aquí reivindicar una suerte de historia imparcial, propia de la tradición premoderna, deudora de un realismo ingenuo, que se puede rastrear en tres imágenes. La primera, ya planteada en Luciano, que alude a la historia como un espejo; es decir, la historia debía reflejar como un espejo, la verdad sin deformaciones ni coloraciones que no se encuentren en el original. En 1623, Gerhard Voss seguía definiendo a la historia como speculum vitae humana y todavía después de la Ilustración, en 1779, Johan Halle consideraba que la historia ofrecía a los hombres un espejo desinteresado de sus deberes y obligaciones (Koselleck, 1993).

La segunda imagen, en verdad una variación de la anterior, es la de la historia desnuda, es decir, la de la transmisión de los hechos tal como han ocurrido, que todavía utilizaría Ranke en sus trabajos tempranos, como una herramienta para desenmascarar la historia falsa.

Y la tercera imagen, es la de la historia apolítica, también atribuida a Luciano. Pero hay que entender aquí el sentido netamente clásico del término. Apolítica porque el historiador no pertenece a la polis, es decir, viene a ser un extranjero a la polis. Es la imagen del historiador externo y totalmente descomprometido de los hechos que narra. Todavía Ranke pretendía que el historiador diera cuenta de la totalidad con los hechos, que describiera la verdad tal "como se ha producido exactamente" (wie es eigentlich gewesen), sin tomar partido o en todo caso incluyendo a todos los partidos, es decir a todas las partes (Carbonell, 1986, p. 119).

Johann Martin Chladenius a comienzos del siglo XVIII introdujo una modificación de envergadura. Si el historiador sabía antiguamente que era necesario interrogar a diferentes testigos para intentar comprender las diferentes partes de la historia, ¿no implicaba ello que también el historiador tenía su propia perspectiva? En ese sentido, el ideal del historiador imparcial, externo, capaz de reflejar la verdad como un espejo, parece una absoluta imposibilidad (Koselleck, 1993).

Ahora bien, desde esta línea argumentativa, parecería que la historia de Boring o de Jones tendría la misma pretensión de verdad que cualquier otra. Sin embargo, la filosofía de la historia y la teoría de la historia no se han limitado a reconocer el aspecto perspectivista de la historia. Desde la modernidad, esa misma posición perspectivista incluyó dos elementos nuevos: el ejercicio crítico y reflexivo no 
sólo sobre las fuentes y testimonios (Bloch, 1952) sino también sobre la propia perspectiva del historiador y sobre el conjunto de la historiografía anterior. En ese sentido:

Ya no se rememora el pasado mediante la tradición oral o escrita; más bien se reconstruye con un procedimiento crítico.....Una vez que ha transcurrido el tiempo suficiente, se manifiesta el pasado gracias a la 'crítica histórica' que sabe tomar en cuenta las perplejidades polémicas de sus antecesores de una forma completamente diferente. (Koselleck, 1993, p. 187; las bastardillas en el original)

El cuestionamiento a la tradición historiográfica anglosajona y a la tradición historiográfica psicoanalítica, en consecuencia, no se deriva del hecho de su evidente parcialidad. Se deriva de la imposibilidad que esa imparcialidad generaba de revisar críticamente todo el proceso de producción historiográfica, empezando por la teoría subyacente del sentido histórico atribuido al método experimental en un caso y a los procesos inconscientes relacionados con la sexualidad en el otro, y finalizando con el proceso de recorte, selección y autenticación de las fuentes utilizadas.

Directamente relacionado con el relevo de fuentes, se encuentra el controvertido concepto de dato histórico. En esa dirección, el historiador Bevir (1993) reconoce que todo dato adquiere significado en el marco de una determinada explicación:

Las interpretaciones no solamente revelan el carácter de los hechos; inclusive crean el carácter de los hechos y, más aún, ellas orientan nuestras decisiones sobre lo que constituyen los hechos (Bevir, 1994, p. 334; la traducción nos pertenece).

En efecto, la filosofía de la historia y la teoría de la historiografía de nuestros días, desde la Escuela de Frankfurt y la nouvelle histoire, hasta el movimiento de Historia a Debate, han enfatizado que el trabajo del historiador se mueve entre dos polos: el de la "objetivad" relacionada con las técnicas que dispone el historiador para verificar la autenticidad de las fuentes originales, la cantidad y calidad de fuentes a consultar, etc., por una parte, y el de la "subjetividad" o el juicio del historiador sobre esas mismas fuentes, o, como también se ha llamado, sobre la teoría histórica que selecciona y en ese sentido, construye esas fuentes, por la otra.
Si el punto de partida de la Historia de la Psicología Experimental de Boeing (1950) derivaba del valor que le otorgaba al método experimental y a su concepción de que dicho método no debía someterse a las exigencias de la psicología aplicada ni de los planteos metafísicos, todo el proceso de análisis y recorte de fuentes queda limitado por aquella problemática teórica. Por tal razón, por ejemplo, Boring, que conocía bien la tradición de la psicología francesa, la limitó, en su edición de 1929, a un pequeño apéndice que no llegaba a siete páginas. Desde su postura la psicología francesa era simplemente psicología médica y se mantuvo alejada del "corazón de la psicología experimental" (Boring, 1929, p. 665, la traducción me pertenece).

De manera análoga, los antecedentes filosóficos de la psicología experimental se redujeron básicamente el asociacionismo inglés mientras la larga tradición de la filosofía alemana del siglo XIX, de Kant a Wundt, apenas se limitó a los planteos de Herbart y Lotze (Boring, 1929).

En el caso de la Vida y Obra de Sigmund Freud, Jones señalaba con claridad las razones que motivaron a escribir su historia: contraponer al héroe a las historias mendaces y a la leyenda negra que comenzaba a circular sobre Freud. La historia del psicoanálisis de Jones (1953-1957) sería la historia de su creador y la historia de su creador será la del héroe, con toda la carga semántica y valorativa implícita en ese concepto. En ese camino, Jones (1976) no ocultó que lo "aterrorizaba" realizar una biografía de Freud pero encuentra los motivos para superar ese terror: que era el único pensador del círculo íntimo de Freud que permanecía con vida, que había sido su amigo durante cuarenta años; que había ocupado un lugar central en el movimiento psicoanalítico; que había sido extranjero y al mismo tiempo, el único gentil del grupo de colaboradores del círculo freudiano. De hecho, aun cuando gentil, el origen galés de Jones lo convertía también en miembro de una minoría (Steiner, 2001; Veszy-Wagner, 1968). Finalmente el factor que terminó de decidir a Jones a escribir la biografía de Freud, fue la publicación del libro de Wittels sobre Freud en 1924, al cual Freud consideró "malo, digno de poca confianza y capaz de confundir a sus lectores" (Jones, 1976, tomo 2, p. 119). Es decir, en todo momento, el propio Jones (19531957) reconocía los objetivos reivindicativos y legitimantes de su historia sobre Freud.

Esta última tradición, de fuerte arraigo en los ámbitos psicológicos dominados por la perspectiva psicoanalítica, ha enfatizado, entre sus núcleos centrales, que toda la psicología del siglo XIX, es 
decir toda la psicología que precede a Freud, podía ser conceptualizada en términos de psicología de la conciencia (Bewusstseinspychologie).

En realidad, el concepto de psicología de la conciencia (Bewusstseinspychologie), fue utilizado por Freud en limitadas oportunidades. En uno de sus trabajos más conocidos, Das Unbewusste (Lo inconsciente), en el apartado "Die Rechtfertigung des Unbewussten" ("Justificación del concepto de inconsciente"), Freíd (1915/1982a) cuestionaba a aquellos que no habían reparado adecuadamente en el valor psicológico de actos fallidos y sueños. Para no reconocer una actividad psíquica inconsciente, argumentaba Freíd (1915/1982a), tales personas necesitaban pasar por alto "einige Rätsel der Bewusstseinspsychologie” ("algunos enigmas de la psicología de la conciencia”) (Freud, 1915/1982a, p. 127, el subrayado y la traducción me pertenecen).

En Das Ich und das Es (El yo y el ello), formulaba cuestionamientos similares. Si numerosas personas con cultura filosófica -afirmaba Freíd (1923/1982b)rechazaban un psiquismo inconsciente, es porque no han estudiado los fenómenos del sueño, la hipnosis y la psicopatología que impone tal concepción. "Ihre Bewusstseinspsychologie ist aber auch unfähig, die Probleme des Traumes und der Hypnose zu lösen" ("Su psicología de la conciencia es sin embargo incapaz de resolver los problemas de los sueños y de la hipnosis") (Freud, 1923/1982b, p. 283. El subrayado y la traducción son míos).

Sin embargo, si las referencias explícitas de Freud a las concepciones que lo precedieron en términos de psicología de la conciencia fuero limitadas, sus alusiones implícitas a las mismas fueron permanentes y siempre con un sentido cuestionador.

Esta tradición pasa rápidamente por alto tres cuestiones. Primero, las diferencias profundas entre esas supuestas psicologías de la conciencia. Segundo, que para muchas de esas psicologías el tema de la conciencia no resulta ni siquiera mínimamente tematizado. Y tercero, que para otras de esas psicologías, los procesos o fenómenos o representaciones inconscientes eran suficientemente conocidos y valorados, aun cuando no existiera ninguna hipótesis de sistema inconsciente vinculado con la sexualidad infantil, como fuera planteado por Freíd (1923/1982b).

De todos modos, esta tradición historiográfica puede fundarse en Freud, pero su carta de ciudadanía la obtuvo con la monumental biografía sobre Freud escrita por Jones (1953-1957). Y, más allá de la obra de Jones, sus alcances desmesuradamente generalizadores exceden ampliamente la responsabilidad tanto de Freud como de Jones. Resulta posible que tal extensión, como en realidad todo mito, se deba mucho más a una tradición oral transmitida de psicoanalista en psicoanalista, de generación en generación y aceptada sin reparos en tanto aparece fuertemente relacionada con la identidad del psicoanalista como tal.

En el caso de la otra tradición historiográfica que estamos analizando, se construyó en los Estados Unidos entre los finales de los años 20 y el final de la Segunda Guerra Mundial. En ella, el papel de la monumental obra de Boring (1950) resultó decisivo. Simplificando los términos, para Boring (1950), la psicología surgió como ciencia independiente cuando en 1879, Wundt introducía el método experimental en la psicología y creaba el Primer Laboratorio de Psicología Experimental en Leipzig.

En todo caso, Boring también reconocía que "el comienzo formal de la psicología experimental comenzaba con Fechner, no con Wundt" (Boring, 1929 , p. 265, la traducción es mía). En la misma dirección, Saul Rosenzweig, quien obtuviera su PhD con Boring en Harvard en 1932 (Winston, 1998), señalaba la fuerte identificación de Boring con Fechner (Rosenzweig, 1987).

Al mismo tiempo, desde mitad de siglo, Boring (1950, 1950/1963b, 1955/1961b, 1963a) comenzó a enfatizar la importancia del Zeitgeist por encima de cualquier individualidad, o interactuando con los grandes hombres, tanto en la segunda edición de su History of Experimental Psychology (Boring, 1950) como en trabajos específicos (Boring, 1955/1961b, 1963a, 1950/1963b). Inclusive, tomó temprano conocimiento de la obra de Kuhn señalando que los grandes eventos de la historia coincidían con las revoluciones kuhnianas (Boring, 1963a).

No obstante ello, el propio Boring señaló que no tenía importancia a quien se considerara el fundador de la psicología experimental, si a Fechner o Wundt, pero consideró que Wundt "es el psicólogo más antiguo en la historia de la psicología" (Boring, 1929, p. 310; la traducción es mía). El valor mítico de esta construcción histórica, ha sido objeto de una severa crítica por parte de la historiografía desde finales de la década del setenta, tanto en Canadá (Danziger, 1979a, 1979b, 1980, 1983; Kelly, 1981), en Estados Unidos (Blumenthal, 1975, 1980; O’Donnell, 1979) y posteriormente también en la bibliografía iberoamericana (Abib, 2005; Klappenbach, 1994; Ovejero Bernal, 1994)

De todos modos, si la obra de Boring, merece numerosos reparos, el reconocimiento hacia la 
misma tampoco puede soslayarse. En ese sentido, la crítica que en los últimos años ha recibido sólo puede entenderse en términos verdaderamente dialécticos.

Por otro lado, el propio Boring, en la primera edición de su obra, de 1929, no ocultaba una psicología fuertemente fragmentada en distintas posiciones. Así, en un párrafo que sería suprimido en la segunda y más conocida edición de su obra en 1950 , se veía obligado a aceptar, al menos, la importancia de dos escuelas, el conductismo y la Gestalt, pero en un marco donde también debía consignar los desarrollos de la escuela de Krüger, de Marburgo y la psicología personalista. Afirmaba allí Boring:

A lo largo de los últimos veinte años, la "nueva" psicología de finales de siglo XIX ha estado dando base a todavía más nuevas psicologías, de las cuales la psicología de la Gestalt en Alemania y el conductismo en Estados Unidos son los ejemplos prominentes. (Boring, 1929, p. 570, la traducción es mía).

En tal sentido, también en este caso, el valor mítico que adquirió la equivalencia entre nacimiento de la psicología científica y creación del Laboratorio de psicología experimental en Leipzig, excede con creces la responsabilidad de Boring. Una vez más, debería adjudicarse a la transmisión oral la vigencia de tal tradición.

Es que una de las características centrales de las tradiciones historiográficas, es brindar identidad a los miembros de un determinado grupo profesional o académico. En ese sentido, como subrayara Paul Roazen:

Las culturas viven gracias a mitos sobre sus historias y Freud entendió la necesidad del hombre de reaccionar ante la experiencia en función de símbolos establecidos. (Roazen, 1978, p. 32)

La razón de esa función mítica hay que buscarla, como ya había analizado Malinowski, en la función social que cumplen los mitos (Malinowski, 1926).

Surge aquí otro problema en relación con las tradiciones historiográficas. Si cumplen una función mítica, ¿no ha enseñado toda la antropología contemporánea y Eliade (1992) es un buen testimonio de ello, que en varios sentidos los mitos son verdaderos? ¿Nos obliga ello a considerar que los contenidos de las tradiciones historiográficas son verdaderos?

La cuestión no es menor. En efecto, el historiador Cohen ha señalado que la oposición entre mito e historia esconde tres supuestos típicos, entre ellos el que remite a la oposición verdad/falsedad: "En el lenguaje cotidiano, mito siempre implica algo fabricado o no verdadero" (Cohen 1997, p. 212; la traducción es mía). Sin embargo, en otro sentido, el mismo Cohen ha puntualizado:

El pasado mitologizado no necesita ser históricamente fiel. Pero si ha de ser eficaz en la persuasión y movilización de la gente en el presente, debe estar sujeto al menos por una concepción amplia de "veracidad" (Cohen, 1997, p. 213-214; la traducción es mía).

Según esta perspectiva, las tradiciones historiográficas, como verdaderos mitos de origen, aportarían significación. Más allá de que esta perspectiva, como apuntara Collins (2003), puede ser considerada otra cara de la oposición entre verdad y falsedad, tiene el interés de que en efecto explica bien el escaso impacto de la investigación histórica académica sobre la comunidad profesional y científica y la vigencia de las tradiciones historiográficas.

En cualquier caso, lo que resulta de interés es que, sin entrar a discutir sobre la veracidad del mito, lo que resulta indudable es que la investigación histórica como especialidad académica tiene por objetivo la reconstrucción histórica a partir de ciertas premisas críticas firmemente establecidas. Desde ya, esas premisas sobre el trabajo del historiador no pueden ocultar que, desde cierto punto de vista, el trabajo del historiador, en tanto constructor de un relato, se mueve en una zona próxima a la construcción de relatos en general. Para el caso de la historia de la psicología lo ha planteado claramente Mills, de Canadá. En su opinión:

Los historiadores difieren de los novelistas ya que los primeros tienen la obligación de avanzar más allá de su esquema imaginativo e incluir los de los demás. Pero tal obligación podría hacer creer a los historiadores que su trabajo consiste en retratar mundos posibles y plausibles en vez de escenarios humanos verdaderos y reales. La buena historia, como la buena literatura, amplía nuestro conocimiento de la naturaleza humana. Y de nuevo como la buena literatura, es la imaginación lo que la alimenta, no nuestro deseo de verdad. (Mills, 2000, p. 410; la traducción es mía) 
Pero aún desde una posición extrema, explícitamente inspirada en las posiciones historiográficas de White (1987), para quien el trabajo histórico es producto de la imaginación y no de la razón, no puede desconocerse que, en última instancia, el historiador, por mucho que se aproxime al novelista, no es enteramente un novelista. El propio Mills reconoce que una diferencia entre la tarea del historiador y el novelista radica en que el historiador "se ocupa de personas que en efecto han tenido una existencia física conocida" (Mills, 2000, p. 410; la traducción es mía).

Retomo todas estas discusiones propias de los historiadores, porque me parece que resistúan el lugar de las tradiciones historiográficas. En primer lugar, carece de sentido descalificarlas como falsas. ¿Podría alguien desconocer la gran cantidad de datos verdaderos presentes tanto en la obra de Boring como en la de Jones? En segundo lugar, menor sentido tendría descalificarlas como mitos, habida cuenta que tienen un impacto decididamente mayor y una significación mucho más destacada que la de las investigaciones de los historiadores profesionales.

Es que las tradiciones historiográficas, están en el corazón de lo que uno de los más destacados historiadores argentinos de la década de 1960, José Luis Romero, denominara la conciencia histórica (Romero, 1943/1988). Romero distinguía dos actitudes históricas, la conciencia histórica, por una parte, y el conocimiento o la ciencia histórica, por la otra. Mientras la primera era constitutivo de procesos de identidad colectivos, la segunda era crítica de la constitución de esos procesos de identidad. En ese sentido, las tradiciones historiográficas de la psicología y el psicoanálisis, son parte nuclear de la conciencia histórica de los propios psicólogos o psicoanalistas.

Que formen parte de la conciencia histórica de los psicólogos y psicoanalistas, no implica desconocer que sus formulaciones originales, en la obra de Jones y Boring respectivamente, respondieron a operaciones historiográficas, parte a su vez de operaciones intelectuales e institucionales altamente organizadas.

En ese sentido, las tradiciones historiográficas mencionadas presentan muchas de las características que Hobsbawm analizara en las tradiciones inventadas, es decir reconstrucciones del pasado fuertemente interesadas desde las posiciones políticas e institucionales presentes. Hobsbawm las define de la siguiente manera:

La 'tradición inventada' implica un grupo de prácticas, normalmente gobernadas por reglas aceptadas abierta o tácitamente y de naturaleza simbólica o ritual, que buscan inculcar determinados valores o normas de comportamiento por medio de la repetición, lo cual implica automáticamente continuidad con el pasado. (Hobsbawm, 2002a, p. 8)

Las tradiciones a las que se refiere Hobsbawm (2002a) involucran prácticas comportamentales o materiales bien específicas, desde ceremonias públicas, pasando por cenas de ex alumnos de universidades, hasta monumentos o edificios públicos, y no sólo prácticas discursivas. Pero así como la educación primaria constituyó una forma de tradición inventada para la Tercera República francesa (Hobsbawm, 2002b), considero que las tradiciones historiográficas comparten la lógica de la tradición inventada por tres razones.

La primera, porque las tradiciones historiográficas cumplen con las tres funciones fundamentales y superpuestas de las mismas señaladas por Hobsbawm (2002a): a) establecer cohesión social o coherencia al grupo; b) establecer o legitimar instituciones o relaciones de autoridad; c) socializar, inculcar creencias, sistemas de valores o comportamientos.

$\mathrm{La}$ segunda, es que "todas las tradiciones inventadas, hasta donde les es posible, usan la historia como legitimadora de la acción y cimiento de la cohesión del grupo" (Hobsbawm, 2002a, p. 19). En esa dirección, podría afirmarse que la tradición historiográfica anglosajona y psicoanalítica, no obstante ser en sí mismas tradiciones inventadas, forman parte, a su vez, de tradiciones inventadas más amplias, la tradición de la psicología anglosajona y la tradición del psicoanálisis, en cada caso.

Y la tercera razón, íntimamente relacionada con la anterior, es que la tradición inventada incorpora "las conmemoraciones de figuras notables del pasado" (Hobsbawm, 2002b, pp. 282-283).

En ese sentido, la Historia de la psicología experimental de Boring (1950) puede leerse, y en efecto, así ha sido leída, como una gran conmemoración a la creación del Primer Laboratorio de Psicología Experimental en Leipzig. Y la Vida y Obra de Sigmund Freud, desde ya, como una gran conmemoración al creador del psicoanálisis.

En cualquier caso, esas historias míticas, como analizara Kelly (1981), interesan mucho más por las sugerencias y sutiles alternativas históricas que ocultan que por lo que verdaderamente afirman. En relación con lo primero, las sugerencias, ya se ha 
indicado que en la dedicatoria a Titchener, $L a$ historia de la psicología experimental de Boring establecía una filiación que iba de Wundt a Titchener y de Titchener al propio Boring. En esa dirección la historia de la psicología experimental más que un estudio sobre el pasado de la psicología resultaba una afirmación de la psicología que el propio Boring llevaba a cabo.

En cuanto a las alternativas, el propio Roback (1952) hizo notar el escaso papel que le otorgó Boring a Münsterberg. En efecto, en poco menos de dos páginas resume Boring el desempeño de Münsterberg. Y no sólo es la cantidad, lo hace en un apartado titulado la "periferia de la psicología experimental", en el cual señala que cuando Münsterberg se estableció definitivamente en Harvard en 1897 (ya había estado entre 1892 y 1895), el plan que había ideado nunca se concretó. Y concluía Boring: "No hay casi nada importante en la psicología experimental conectado con el nombre de Münsterberg, con excepción de algunos pequeños experimentos en su Beiträge correspondientes a los días de Friburgo" (Boring, 1929, p. 421). Los cuestionamientos al conductismo fueron todavía más evidentes en su trabajo; Boring afirmaba que el conductismo había surgido para encontrar una necesidad práctica inmediata, por lo cual carecía de sofisticación histórica y resultaba "filosóficamente inepto" (Boring, 1929, p. 494; la traducción es mía).

En cualquier caso, la filiación entre Boring y su maestro Titchener, por una parte, y la obra de Wundt por otra, también resultaba útil para reparar el hecho de que Boring nunca había estado en Alemania, como fuera subrayado por el propio Boring en su autobiografía:

Nunca he estado en Alemania. Esa falta en mi formación fue tema de cierta vergüenza e inclusive cierta amargura antes de que Hitler destruyera la ciencia alemana... Lo que pude hacer fue compensar esa deficiencia. Escribí mi Historia de la psicología experimental en gran parte sobre la psicología alemana, con un mapa de las universidades alemanas en los retiros de tapa y contratapa. Cuando luego de la muerte de G. E. Müller, psicólogos alemanes me escribieron para hacerme preguntas sobre su propio compatriota, sentí que había triunfado. (Boring, 1961a, p. 4142; la traducción es mía).

En cualquier caso, cabe un interrogante ¿porqué los psicólogos orientados hacia el conductismo adoptaron esa tradición historiográfica que se había organizado con la finalidad, por así decirlo, de "desprestigiarlos" exhibiendo un linaje europeo ajeno a los intereses pragmáticos del conductismo?

No hay una respuesta simple, pero resulta interesante el análisis de O'Donnell (1979). Para los conductistas, igual que para los "experimentalistas" seguidores de Titchener y Boring (Goodwin, 2005), Wundt era una figura ilustre, perteneciente a una tradición con la cual, además, ya no competían. Se podría afirmar que el conductismo había adquirido tal envergadura alrededor de 1930, que el "rescate" mítico de Wundt, una figura tan alejada del conductismo, le otorgaba cierto brillo como parte del pasado de una psicología (conductista) que había progresado desde aquel pasado hasta el "presente" conductista.

De todas manera, todavía queda el interrogante de porqué, a pesar de la caída del conductismo, la misma tradición historiográfica que había resultado útil para enfatizar una tradición de la psicología experimental ajena a los intereses prácticos del conductismo, que igualmente fue rescatada por el conductismo, todavía sigue vigente, no obstante las numerosas críticas iniciadas a mitad de la década de 1970.

En esa dirección, Bruner (1991) considera que la llamada "revolución cognitiva" -concepto que autores como Leahey (1992) o Mandler (2002) ponen en cuestión, de fines de los sesenta y de los setenta, fuertemente crítica de los modelos conductistas, había terminado por "fusionarse" con el conductismo en esa suerte de psicología "cognitiva-comportamental", próxima a las ciencias biológicas pero muy alejada de las ciencias humanas y sociales. Siguiendo esas reflexiones, se podía afirmar, entonces, que, para esa tradición de la psicología, no resulta inadecuada la vigencia de aquella antigua tradición historiográfica.

Otra razón de esa vigencia puede fundamentarse en un estudio de Friman, Allen, Kerwin y Larzelere (1993), quienes analizaron la producción cuantitativa de publicaciones norteamericanas, llegando a la conclusión de que a comienzos de la década de 1990, en la psicología norteamericana coexistían por igual los modelos conductistas, cognitivos y aun los psicoanalistas. Desde esa línea de análisis, se podría sostener que existen motivos para que aquella antigua tradición historiográfica continúe vigente, al menos para los que adhieren a postulados conductistas.

En cualquier caso, lo que atraviesa por igual a todas esas posibles líneas argumentativas, es lo que 
subrayaba Kelly (1981). Boring "inventó" el pasado de la psicología y esa construcción intelectual respondía a sus intereses particulares en ese momento. No obstante ello, no puede desconocerse que su trabajo historiográfico incorporó numerosos "conocimientos" históricos, y tal vez en eso radique su fortaleza (y no sólo corresponda centrarse en sus aspectos míticos). Si aquí enfatizamos los aspectos míticos de la tradición anglosajona es porque adherimos a una perspectiva crítica de la historia de la psicología, aun cuando ella no pretenda invalidar, en su conjunto, los aportes que realizó Boring (y de manera análoga los que realizara Jones, para la tradición historiográfica psicoanalítica).

En el caso de la Vida y obra de Sigmund Freud, de nuevo la sugerencia establece una filiación entre Freud, Anna Freud, a quien está dedicado el libro y el propio Jones. El psicoanálisis practicado por Freud parece ser el institucionalizado precisamente en esos años por la International Psychoanalytical Associacion (IPA). No resulta casual que Jones señalara en el segundo tomo de su obra que él mismo fue el primer psicoanalista sometido al análisis didáctico, insistencia en esos años de la IPA como condición sine quanon para convertirse en psicoanalista. No importa tanto que Roazen (1978) señalara que posiblemente ese dato fuera falso. Importa mucho más que la institución del análisis didáctico implicaba opciones metodológicas pero sobre todo de selección de analistas, algo vital para una profesión que se estaba expandiendo aceleradamente.

Por lo pronto, los disensos con Freud, fueron interpretadas por problemas de resistencias que representaban expresiones de rebelión infantil contra la figura paterna:

(...)ninguno de los otros pioneros llegó a conocer gran cosa de su propio inconsciente, o bien lograron esto tan sólo en forma de rápida vislumbres; si bien teóricamente habría sido factible predecir posibles recaídas entre los analistas, semejantes a los que conocemos muy bien en el caso de nuestros pacientes, las primeras experiencias de esta índole resultaron inesperadas y sorprendentes. (Jones, 1976, tomo 2, p. 140)

En esa dirección, Jones consideraba que lo que “Adler podía ofrecer era tan superficial y realmente trivial que raras veces podía interesar a un serio investigador" (Jones, 1976, tomo 2, p. 151). Y aún cuando en su opinión Jung era una persona de gran formación y cultura, citaba una carta de Freud en la cual éste señalaba que "es posible que estemos sobrevalorando a Jung y sus acciones para el futuro" (Paskaukas, 2001, p. 336).

Más allá de esas valoraciones, lo que era claro en la obra de Jones, es que reconocía que la Historia del Movimiento Psicoanalítico escrito por Freud en 1914, tenía el objetivo de afirmar que Freud, "más que ningún otro" era el indicado para saber qué era el psicoanálisis "y cuales eran los métodos y las teorías característicos que lo distinguían de las otras ramas de la psicología" (Jones, 1976, tomo 2, p. 165).

En esa misma dirección, uno de los objetivos estratégicos de la obra de Jones era desacreditar las desviaciones de la obra de Freud; las clásicas de Adler y Jung y las de Rank o Ferenczi posteriormente. En esa dirección, en el tomo tercero de su biografía de Freud, Jones cuestionaba el aislamiento de Ferenczi en razones de salud mental, lo cual motivó que Fromm considerara esa manera de escribir historia con el calificativo de stalinista:

Considero que la cuestión principal es el tipo de reescritura de la historia típicamente estalinista, por la cual los estalinistas difamaban a sus oponentes denominándolos espías y traidores. Los freudianos lo hacen llamándolos insanos. (Carta de Fromm a Izzette de Forest, citada por Bolomi, 1998, p. 202-203; la traducción es mía).

Para la conciencia psicoanalítica, era necesario reverenciar a Freud. Tal objetivo, justificaba el celo de la familia de Freud ante buena parte de las fuentes originales freudianas (Gay, 1989), como también la omisión de Jones por aquellos acontecimientos capaces de enturbiar al psicoanálisis, desde las transgresiones, episodios psicóticos, hasta suicidios, como los de Víctor Tausk, Herbert Silberer o Tatiana Rosenthal (Roudinesco \& Plon, 1998). En su propia autobiografía, Jones (1959) desmintió que Freud fuera tratado por los psicoanalistas como el Papa pero, no obstante, reconoció que algo de verdad podía haber en aquella imagen caricaturizada y el nombre "movimiento psicoanalítico" evocaba a los movimientos políticos o religiosos. La devoción a Freud, en cualquier caso, no fue originaria de Jones. Antes de su biografía, Hirtschmann ya había caracterizado su vida como heroica, la cual en sus últimos instantes había merecido el cuidado tierno de su hija Anna (Hirtschmann, 1944).

Recientemente lo ha señalado Lore Reich-Rubin, en un trabajo destinado a rescatar la figura de su padre, Wilhelm Reich. La hija de Reich demuestra 
que la raíz de los conflictos entre los dos Freud, Sigmund y Anna, por una parte, y Wilhelm Reich, por la otra, fueron simplemente ideas políticas:

Ellos [los psicoanalistas] tendían a reverenciar a Freud y si disentían con él, sutilmente modificaban sus ideas en trabajos posteriores, atribuyendo esas ideas a Freud. No hay dudas de que en 1932 mi padre ya no era un miembro apreciado por los Freuds, y él lo sabía; en consecuencia no siguió ocultando su desacuerdo con ellos. (Reich-Rubin, 2003, p. 111; la traducción es mía).

En esa dirección, se ha señalado la responsabilidad de Jones en el proceso de arianización de la Deutsche Psychoanalytische Gesellschaft luego de las leyes nazis de 1933. Recientemente Nizschke (2003) en una bien documentada investigación, ha reconstruido una parte central de los objetivos de la incorporación de la Deutsche Psychoanalytische Gesellschaft a la Deutsches Institut für psychologische Forschung und Psychotherapie, de tendencia nazi.

Aquella incorporación estaba directamente relacionada con la expulsión de Wilhelm Reich, tanto de la sociedad alemana como de la IPA, expulsión que fue cuidadosamente preparada por los líderes locales de la sociedad psicoanalítica alemana, Felix Boehm y Carl Müller-Braunschweig, y sobre todo por Jones, entonces presidente de la IPA y una de las personas que diseñó el llamado "salvataje" del psicoanálisis en la Alemania nazi (Nizschke, 2003). No obstante, se ha señalado que el malestar con Reich por su filiación al Partido Comunista provenía tanto de Sigmund Freud como de Anna Freud y que la decisión que Jones llevó adelante estaba en verdad encomendada por aquellos (ReichRubin, 2003; Roudinesco \& Plon, 1998).

En tal sentido, la Vida y Obra de Sigmund Freud establece una clara filiación entre Sigmund Freud, Anna Freud y Ernest Jones. En una de las primeras biografías del propio Jones, a cargo de Veszy-Wagner (1968), se señalaron todas las similitudes vitales entre Freud y Jones, desde que en la infancia ambos gozaron de ser hijos predilectos, hasta los temores por la celebración del octogésimo aniversario, pasando por la característica de ambos de incluir actos fallidos y sueños personales en sus trabajos. Y concluía VeszyWagner (1968, p. 69): “En síntesis, el valor autobiográfico de la biografía de Freud [de Jones] es realmente único". En esa dirección, Jones venía a resultar el alter ego de Freud (Brome, 1983).
Por tal razón, la perspectiva de la obra historiográfica de Jones es la misma de la Autobiografía (Freud, 1925/1976b) y de la Historia del movimiento psicoanalítico (Freud, 1914/1976a) del propio Freud. Como afirmara Paul Roazen, uno de los más agudos y críticos estudiosos de la historia freudiana:

En general, la perspectiva desde la que Jones vio la vida de Freud y sus muchas controversias siguió siendo la del propio Freud. Jones cumplió su misión fundamental de biógrafo oficial... Como ha ocurrido con otras notables biografías autorizadas, gran parte de lo que los futuros historiadores conocerán sobre Freud lo ha proporcionado la documentación de Jones. (Roazen, 1978, p. 10)

En definitiva, las personalidades encargadas de la invención de las tradiciones que estamos analizando, no se caracterizaron por su formación como historiadores. Al contrario, tanto Boring como Jones eran personalidades fuertemente comprometidas con las instituciones de la psicología y del psicoanálisis de su tiempo, respectivamente (ver tabla 1). Boring no solamente había sido el responsable de la autonomía del Departamento de Psicología de la Universidad de Harvard y su primer director, Presidente de la American Psychological Association, sino también el autor de los reconocidos libros de texto editados en colaboración con Langfeld y Well, de gran circulación en la enseñanza de la psicología norteamericana (Boring, Langfeld, \& Weld, 1935, 1937, 1939, 1948). Con razón, se puede sintetizar que Boring era "uno de los psicólogos más influyentes del período de entreguerras, tanto desde el punto de vista del poder formal institucional como desde el informal generado por su status profesional" (Winston, 1998, p. 45, la traducción es mía).

Jones, por su parte, no solamente fue uno de los introductores del psicoanálisis en Norteamérica, Canadá e Inglaterra, sino también uno de los principales impulsores del análisis didáctico. Promovió la traducción de las obras de Freud al inglés y presidió la IPA en momentos particularmente difíciles, en especial durante el auge del nazismo y de la Segunda Guerra Mundial (Brome, 1983). No resulta casual que Freud lo escogiera en 1912 como uno de los miembros del llamado Comité Secreto, que el propio Jones impulsara, junto con Abraham, Ferenczi, Rank, 
Sachs y von Freund como miembro adjunto, con el objetivo de proteger al psicoanálisis de desviaciones, como fueron interpretadas por Freud las teorías de Adler, Stekel y Jung (Jones, 1952-1957). En síntesis, "su habilidad diplomática y su excepcional conocimiento de las condiciones profesionales en Europa, en Gran Bretaña y en los Estados Unidos, hacían de él [Jones] la persona ideal para actuar como administrador de la Asociación Psicoanalítica Internacional" (Veszy-Wagner, 1968, p. 20).

Tabla 1. Cuadro Comparativo de la Producción y Posiciones Académicas de Edwin Boring y Ernest Jones

\begin{tabular}{|c|c|c|}
\hline & Edwin Garrigues Boring & Ernest Jones \\
\hline $\begin{array}{l}\text { Nacionalidad y } \\
\text { años de vida }\end{array}$ & Norteamericano (1886-1968) & Inglés (galés) (1879-1958) \\
\hline $\begin{array}{l}\text { Relación con la } \\
\text { enseñanza y la } \\
\text { formación }\end{array}$ & $\begin{array}{l}\text { 1914-1918: Instructor en Cornell University } \\
\text { 1919-1922: Profesor en Clark University } \\
\text { 1922- 1968: Profesor en Harvard } \\
\text { 1924-1950: Director del Laboratorio de Harvard } \\
\text { 1933-1934: Organizador Dpto. de Psicología. Harvard } \\
\text { 1936-1938: Director Dpto. de Psicología. Harvard }\end{array}$ & $\begin{array}{l}\text { 1924-1948: Profesor en el Institute of Psychoanalysis de Londres } \\
\text { 1926: Fundador de la London Clinic of Psychoanalysis } \\
\text { 1926-1932: Presidente del International Training Committee }\end{array}$ \\
\hline $\begin{array}{l}\text { Sociedades } \\
\text { científicas que } \\
\text { organizaron o } \\
\text { presidieron }\end{array}$ & $\begin{array}{l}\text { 1922: American Psychological Association (Secretario) } \\
\text { 1928-1929: American Psychological Association (Presidente) } \\
\text { 1929: } 9^{\circ} \text { Congreso Internacional de Psicología. Universidad de Yale, } \\
\text { New Haven (USA). } 1^{\circ} \text { al } 7 \text { de septiembre. Secretario y Editor de } \\
\text { Actas. } \\
\text { 1961-1962: New England Psychological Association (Presidente) }\end{array}$ & $\begin{array}{l}\text { 1911: Asociación Psicoanalítica Americana (Fundador) } \\
\text { 1913: London Psychoanalytical Society (Fundador) } \\
\text { 1919: British Psychoanalytical Society (Fundador) } \\
\text { 1912-1927: Miembro del "Comité Secreto" } \\
\text { 1920-1924 y 1932-1949: International Psychoanalytical Association } \\
\text { (Presidente) } \\
\text { 1921-1950: International Psycho-Analytical Library (Hogarth Press - } \\
\text { Institute of Psycho-Analysis) (Fundador) }\end{array}$ \\
\hline $\begin{array}{l}\text { Publicaciones } \\
\text { periódicas o } \\
\text { colecciones que } \\
\text { dirigieron }\end{array}$ & $\begin{array}{l}\text { 1926-1946: American Journal of Psychology } \\
\text { 1920-1922: American Psychological Association Yearbook } \\
\text { 1930: Proceedings and Papers. IX International Congress of } \\
\text { Psychology } \\
\text { 1956-1959: Contemporary Psychology } \\
\text { 1965-1968: Journal of the History of the Behavioral Sciences } \\
\text { (Miembro del Editorial Board) }\end{array}$ & $\begin{array}{l}\text { 1910-1921: Journal of Abnormal Psychology (Assistant Editor) } \\
\text { 1913-1919: Internationale Zeitschrift für ärztliche Psychoanalyse } \\
\text { 1920-1922: British Journal of Psychology. Medical Section } \\
\text { 1920-1939: International Journal of Pycho-Analysis (fundador) } \\
\text { 1923-1950: British Journal of Medical Psychology }\end{array}$ \\
\hline $\begin{array}{l}\text { Obras publicadas } \\
\text { principales }\end{array}$ & $\begin{array}{l}\text { 1913: Learning in dementia precox } \\
\text { 1929: History of Experimental Psychology } \\
\text { 1933: Physical dimensions of consciousness } \\
\text { 1935: Psychology, a factual textbook } * \\
\text { 1937: A Manual of psychological experiments * } \\
\text { 1939: Introduction to Psychology * } \\
\text { 1942: Sensation and perception in the history of experimental } \\
\text { psychology } \\
\text { 1950: History of Experimental Psychology }\left(2^{\text {nd }} \mathrm{ed} .\right) \\
\text { 1961: Pscyhologist at large (autobiografía) } \\
* \text { Obras en colaboración }\end{array}$ & $\begin{array}{l}\text { 1913: Papers on Psychoanalysis } \\
\text { 1920: The treatment of the neurosis. } \\
\text { 1923: Essays in Applied Psychoanalysis } \\
\text { 1924: Social aspects of psychoanalysis } \\
\text { 1929: Psycho-analysis } \\
\text { 1931: On the nightmare } \\
\text { 1949: Hamlet and Oedipus } \\
\text { 1953-1957: Sigmund Freud. Life and work } \\
\text { 1959: Free associations: Memories of a psychoanalyst } \\
\text { (autobiografía). }\end{array}$ \\
\hline Antecedentes & 1921: Titchener: Wundt (Titchener, 1921) & $\begin{array}{l}\text { 1914: Freud: Historia del movimiento psicoanalítico (Freud, } \\
\text { 1914/1976a) }\end{array}$ \\
\hline Fuentes & $\begin{array}{l}\text { Boring, 1913, 1929, 1933, 1942; 1950, 1952; 1961; Boring, } \\
\text { Langfeld \& Weld, 1935, 1937, 1939, 1948; Jaynes, 1969; Kelly, } \\
\text { 1981; O’Donnell, 1979; Osier \& Wozniak, 1984; Rosenzweig, 1987; } \\
\text { Winston, } 1998\end{array}$ & $\begin{array}{l}\text { Brome, 1983; Jones, 1913, 1920, 1923, 1924, 1929, 1931, 1949, } \\
\text { 1953-57, 1959; Osier \& Wozniak, 1984; Paskaukas, 2001; } \\
\text { Roudinesco \& Plon, 1998; Steiner, 2001; Veszy-Wagner, 1968; }\end{array}$ \\
\hline
\end{tabular}

Ese fuerte compromiso de Boring hacia la psicología norteamericana y de Jones hacia el psicoanálisis, entonces, ha sido bien analizado en las valoraciones contemporáneas. En relación con la historia de Boring, Kelly señaló:

La historia de la psicología, como ha sido escrita típicamente, es historia "whig"; es decir, constituye un relato de los éxitos y fracasos de la psicología escrita por aquellos con marcados intereses, deliberadamente reconocidos o no, en la exaltación de determinados éxitos y en la prudente exhibición de determinados fracasos..... Gran parte de la historia de la psicología debe ser entendida en esos términos. Un importante caso al respecto es gran parte del trabajo del más influyente historiador de la psicología de este siglo, E. G. Boring. (Kelly, 1981, p. 229; la traducción es mía).

En relación con la obra de Jones (1953-1957), un psicoanalista argentino, bien conocido internacionalmente, Rodrigué, sintetizaba: 
[La Vida y Obra de Sigmund Freud] tiene algo de empresa faraónica; cae en la tentación de levantar un mausoleo para la veneración de las generaciones futuras. Pocas veces hubo una biografía tan 'comprometida', con alma de texto apostólico, expresión tan cabal de la leyenda y la doctrina freudianas. (Rodrigué, 1996, p. 10)

Desde ya, es posible reconocer otras tradiciones historiográficas en el campo de la psicología. Desde Binet (1894/1906) hasta Canguilhem (1958), es posible identificar una tradición historiográfica francesa, que ha tenido el mérito indudable de reconocer que los orígenes de la psicología como disciplina científica en modo alguno pueden limitarse a la introducción del método experimental o al así llamado descubrimiento del inconsciente.

Asimismo, es posible mencionar una tradición historiográfica referida exclusivamente al campo de la psicología social. El análisis crítico que Samelson (2000) realizara sobre el Handbook of social psychology de Lindzey, cuya primera edición se publicara en 1954, pocos años después de la segunda edición de Boring (Lindzey, 1954) y la cuarta y última edición en 1998 (Gilbert, Fiske \& Lindzey, 1998), permite visualizar allí todos los rasgos que hemos examinado de una tradición historiográfica. Inclusive, el propio Samelson se refiere explícitamente a los elementos whigistas presentes en la introducción histórica a cargo de Allport (1954) en las tres primeras ediciones, eliminado en la última edición sin ningún tipo de comentario. En la misma dirección, Danziger (2000) ha señalado la invención de una psicología social de carácter experimental y califica a aquella introducción histórica en el manual de Lindzay con el apelativo de historia casi-oficial.

En síntesis, aun cuando puedan existir otras tradiciones historiográficas en el campo de la psicología, la tradición historiográfica anglosajona y la tradición historiográfica psicoanalítica parecen las dos tradiciones más firmemente arraigadas en las comunidades profesionales a las que están dirigidas: la comunidad psicológica anglosajona y la comunidad psicoanalítica respectivamente. Ambas tradiciones pueden considerarse invenciones, en el sentido de Hobsbawm, es decir construcciones intelectuales comprometidas con los acontecimientos institucionales en las cuales emergieron, cada una a su modo. En tal sentido, la función de las mismas no es tanto la de aportar conocimientos sobre el pasado histórico como socializar a los miembros de las comunidades a las que están dirigidas, brindando cohesión social y de tal manera otorgar legitimidad a determinadas instituciones.
Ambas tradiciones historiográficas, entonces, se pueden inscribir dentro de una perspectiva militante y legitimadora de la historia que tan magistralmente describía para una hipotética sociedad futura George Orwell en 1984: "Quien es dueño del pasado rezaba un lema del partido- domina el porvenir; el que es dueño del presente, domina el pasado" (Orwell, 1951, p.47).

\section{Agradecimientos}

El autor agradece comentarios críticos de Patricia Altamirano, Julio del Cueto, Alejandro Dagfal, Lucía Rossi, Aaron Saal y Ramón Sanz Ferramola a una versión previa del trabajo.

\section{REFERÊNCIAS}

Abib, J. A. D. (2005). Prólogo à historia da Psicologia. Psicologia: Teoria e Pesquisa, 21(1), 53-60.

Allport, G. W. (1954). The historical background of modern Social Psychology. In G. Lindzey (Ed.), Handbook of social psychology (Vol. 1, pp. 3-56). Reading: AddisonWesley.

Bevir, M. (1994). Objectiviy in history. History and Theory, 9 , 328-344.

Binet, A. (1906). Introducción a la psicología experimental. Madrid: Daniel Jorro. (Originalmente publicado en 1894).

Bloch, M. (1952). Introducción a la Historia. México: Fondo de Cultura Económica.

Blumenthal, A. (1975). A reappraisal of Wilhelm Wundt. American Psychologist, 30, 1081-1088.

Blumenthal, A. (1980). Wilhelm Wundt: Problems of interpretation. In W. Bringmann \& R. Tweney (Eds.), Wundt studies (pp. 435-445). Toronto: Hogrefe.

Bolomi, C. (1998). Jones's allegation of Ferenczi's mental deterioration: A reassessment. International Forum for Psychoanalysis, 6, 201-206.

Boring, E. G. (1913). Learning in dementia precox. Princeton/Lancaster: Psychological Review Co.

Boring, E. G. (1929). A history of experimental psychology. New York: Appleton-Century Co.

Boring, E. G. (1933). The physical dimensions of consciousness. New York-London: The Century Company

Boring, E. G. (1942). Sensation and perception in the history of experimental psychology. New York/London: D. Appleton-Century Company.

Boring, E. G. (1950, $2^{\mathrm{a}}$ ed.). A history of experimental psychology. New York: Appleton-Century.

Boring, E. G. (Ed.) (1952). A history of psychology in autobiography (Vol. 4). Worcester: Clark University Press.

Boring, E. G. (1961a). Psychologist at large. In E. G. Boeing (Ed.), Psychologist at large: An autobiography and selected essays (pp. 3-83). New York: Basic Books.

Boring, E. G. (1961b). Dual role of the Zeitgeist in scientific creativity. In E. G. Boeing (Ed.), Psychologist at large: An 
autobiography and selected essays (pp. 325-337). New York: Basic Books. (Originalmente publicado en 1955).

Boring, E. G. (1963a). Eponym as placebo. In R. Watson \& D. Campbell (Eds.), Edwin G. Boring: History, psychology and science: Selected papers (pp. 5-25). New York/London: J. Wiley \& Sons.

Boring, E. G. (1963b). Great men and scientific progress. In R. Watson \& D. Campbell (Eds.), Edwin G. Boring. History, psychology and science: selected papers (pp. 29-49). New York-London: J. Wiley \& Sons. (Originalmente publicado en 1950).

Boring, E. G., Langfeld, H. S. \& Weld, H. P. (Eds.) (1935). Psycholog: A factual textbook. New York/London: J. Wiley \& Sons/Chapman \& Hall.

Boring, E. G., Langfeld, H. S. \& Weld, H. P. (Eds.) (1937). A manual of Psychological experiments. New York/London: J. Wiley \& Sons/ Chapman \& Hall.

Boring, E. G., Langfeld, H. S. \& Weld, H. P. (Eds.) (1939). Introduction to Psychology. New York/London: J. Wiley \& Sons/Chapman \& Hall.

Boring, E. G., Langfeld, H. S. \& Weld, H. P. (Eds.) (1948). Foundations of Psychology. New York: J. Wiley.

Brock, A. (1993). Something old, something new: The 'reappraisal' of Wilwelm Wundt in Textbooks. Theory \& Psychology, 3(2), 235-242.

Brock, A. (en prensa). Introduction: The difference between US history and world history. In A. Brock (Ed.), Internationalizing the history of psychology. New York: New York University Press.

Brome, V. (1983). Ernest Jones: Freud's alter ego. New York: Norton.

Bruner, J. (1991). Actos de significado: más allá de la revolución cognitiva. Madrid: Alianza.

Canguilhem, G. (1958). Qu'est-ce que la psychologie. Revue de Mètaphysique et de Moral, 63(1), 12-25.

Carbonell, C. O. (1986). La historiografía. México: Fondo de Cultura Económica.

Cohen, P. A. (1997). History in three keys: The boxers as events, experience and myth. New York: Columbia University Press.

Collins, R. (2003). Concealing the poverty of traditional historiography: Myth as mystification in historical discourse. Rethinking History, 7(3), 341-365.

Danziger, K. (1979a). The positivist repudiation of Wundt. Journal of the History of the Behavioral Sciences, 15, 205230.

Danziger, K. (1979b). The social origins of modern psychology. In A. R. Buss (Ed.), Psychology in social context (pp. 25-44). New York: Irvington Publishers.

Danziger, K. (1980). Wundt's psychological experiment in the light of his philosophy of science. Psychological Research, 42, 109-122.

Danziger, K. (1983). Origins and basic principles of Wundt's Völkerpsychologie. British Journal of Social Psychology, 22, 303-313.
Danziger, K. (1993). Three challenges for the history of psychology. Invited address presented to Division 26 of the American Psychological Association. (Mimeo, Gentileza de Alejandro Dagfal).

Danziger, K. (1994). Does the history of psychology have a future? Theory \& Psychology, 4(4), 467-484.

Danziger, K. (2000). Making social psychology experimental: a conceptual history, 1920-1970. Journal of the History of the Behavioral Sciences, 36(4), 329-347.

Eliade, M. (1992). Mito y realidad. Barcelona: Labor

Freud, S. (1976a). Contribución a la historia del movimiento psicoanalítico. En S. Freud, Obras completas (Tomo 14, pp. 1-64). Buenos Aires: Amorrortu. (Originalmente publicado en 1914).

Freud, S. (1976b). Presentación autobiográfica. En S. Freud, Obras completas (Tomo 20, pp. 1-70). Buenos Aires: Amorrortu. (Originalmente publicado en 1925).

Freud, S. (1982a). Das Unbewubte. En S. Freud, Studienausgabe (Bd. III, pp. 119- 173). Frankfurt am Main: Fischer Taschenbuch Verlag. (Originalmente publicado en 1915).

Freud, S. (1982b). Das Ich und das Es. En S. Freud, Sudienausgabe (Bd. III, pp. 273-330). Frankfurt am Main: Fischer Taschenbuch Verlag. (Originalmente publicado en 1923)

Friman, P. C., Allen, K. D., Kerwin, M. L. \& Larzelere, R. (1993). Changes in modern psychology: A citation analysis of the Kuhnian displacement thesis. American Psychologist, 48(6), 658-664.

Gay, P. (1989). Freud: una vida de nuestro tiempo. Buenos Aires: Paidós.

Gilbert, D., Fiske, S. T. \& Lindzey, G. (Eds.). (1998, 4th ed.). The handbook of social psychology. Boston: McGraw Hill.

Goodwin, C. J. (2005). Reorganizing the experimentalists: The origin of the Society of Experimental Psychology. History of Psychology, 8(4), 347-361.

Hirtschmann, E. (1944). Freud en vida y muerte. Revista de Psicoanálisis, 2(1), 1-32.

Hobsbawm, E. (2002a). Introducción: la invención de la tradición. En E. Hobsbawm \& T. Ranger (Eds.), La invención de la tradición (pp. 7-21). Barcelona: Crítica.

Hobsbawm, E. (2002b). La fabricación en serie de tradiciones: Europa, 1870-1914. En E. Hobsbawm \& T. Ranger (Eds.), La invención de la tradición (pp. 273-318). Barcelona: Crítica.

Jaynes, J. (1969). Edwin Garrigues Boring: 1889-1968. Journal of the History of the Behavioral Sciences, 5, 99112.

Jones, E. (1913). Papers on Psychoanalysis. New York: Wood and Co.

Jones, E. (1920). The treatment of the neurosis. New York: Wood and Co.

Jones, E. (1923). Essays in applied psychoanalysis. London: International Psychoanlytical Press.

Jones, E. (1924). Social aspects of psycho-Analysis. London: Williams and Norgate. 
Jones, E. (1929). Psycho-analysis. New York: J. Cape \& H. Smith

Jones, E. (1931). On the nightmare. London: Hogarth PressInstitute of Psycho-Analysis.

Jones, E. (1949). Hamlet and Oedipus. London: V. Gollancz.

Jones, E. (1953-1957). Sigmund Freud:Life and work. London: Hogarth Press.

Jones, E. (1959). Free asocciations: Memories of a psychoanalyst. London: Hogarth Press.

Jones, E. (1976). Vida y obra de Sigmund Freud. Buenos Aires: Hormé.

Kelly, B. (1981). Inventing Psychology's past: E. G. Boring historiography in relation to the psychology of his time. The Journal of Mind and Behavior, 2(1), 229-241B.

Klappenbach, H. (1994). Diferentes problemas y tradiciones en la psicología del siglo XIX. Idea, 14, 63-80.

Koselleck, R. (1993). Futuro pasado: para una semántica de los tiempos históricos. Barcelona: Paidós Ibérica.

Leahey, T. (1981). The mistaken error: on Wundt's and Titchener's psychologies. Journal of the History of the Behavioral Sciences, 17, 273-282.

Leahey, T. (1992). The mythical revolutions of American Psychology. American Psychologist, 47(2), 308-318.

Lindzey, G. (Ed.) (1954). Handbook of social psychology. Cambridge: Addison-Wesley.

Malinowski, B. (1926). Myth in primitive psychology. London: Kegan Paul, Trench, Tubner.

Mandler, G. (2002). Origins of the cognitive (r)evolution. Journal of the History of the Behavioral Sciences, 38(4), 229-353.

Mills, J. A. (2000). Hard-nosed psychologists: Some reflections on writing psychologys's history. Theory \& Psychology, 10(3), 399.412.

Nizschke B. (2003). Psychoanalysis and national socialism: Banned or brought into conformity? Break or continuity? International Forum for Psychoanalisis, 12, 98-108.

O'Donnell, J. M. (1979). The crisis of experamintalism in the 1920s. E. G. Boring and his uses of history. American Psychologist, 34(4), 289-295.

Orwell, G. (1951, 4ª ed.). 1984 . Buenos Aires: Guillermo Kraft.

Osier, D. V. \& Wozniak, R. H. (1984). A century of serial publications in Psychology: 1850-1950. Millwood: Kraus International Pub.

Ovejero Bernal, A. (1994). Wilhelm Wundt: ¿fundador de la psicología experimental no social o de la psicología social no experimental? Revista de Historia de la Psicología, 15(1/2), 123-150.
Paskaukas, R. A. (Ed.) (2001). Sigmund Freud. Ernest Jones: Correspondencia completa. 1908-1939. Madrid: Síntesis.

Reich-Rubin, L. (2003). Wilhelm Reich and Anna Freud: his expulsion from psychoanalysis. International Forum for Psychoanalysis, 12,109-117.

Roazen, P. (1978). Freud y sus discípulos. Madrid: Alianza.

Roback, A. A. (1952). History of american psychology. New York: Library.

Rodrigué, E. (1996). Sigmund Freud: El siglo del psicoanálisis. Buenos Aires: Sudamericana.

Romero, J. L. (1988). Crisis y salvación de la ciencia histórica. En J. L. Romero, La vida histórica. (pp. 33-39). Buenos Aires: Sudamericana. (Originalmente.publicado en 1943)

Rosenzweig, S. (1987). The final tribute of E. G. Boring to G. T. Fechner. American Psychologist, 42(8), 787-790.

Roudinesco, E. \& Plon, M. (1998). Diccionario de Psicoanálisis. Buenos Aires: Paidós.

Samelson, F. (1999). Assessing research in the history of psychology: past, present and future. Journal of the History of the Behavioral Sciences, 35(3), 247-255.

Samelson, F. (2000). Whig and anti-whig histories and other curiosities of social psychology. Journal of the History of the Behavioral Sciences, 36(4), 499-506.

Schultz, D. P. \& Schultz, S. E. (1996, 6 ${ }^{\text {th }}$. ed.). A history of modern Psychology. Fort Worth: Harcourt Brace \& Co.

Steiner, R. (2001). Introducción. En R. A. Paskauskas (Ed.), Sigmund Freud. Ernest Jones: Correspondencia completa. 1908-1939. (pp. 19-46). Madrid: Síntesis.

Titchener, E. B (1921). Wilhelm Wundt. The American Journal of Psychology, 32, 161-178

Veszy-Wagner, L. (1968). Ernest Jones. En L. Veszy-Wagner \& E. Weiss (1968), Historia del psicoanálisis II (pp. 992). Buenos Aires: Paidós.

White, H. (1987). The content on the form: Narrative discourse and historical representation. Baltimore: John Hopkins University Press.

Winston, A. S. (1998). "The defects of his race": E. G. Boring and antisemitism in American psychology. History of Psychology, 1(1), 27-51.

Zehr, D. (2000). Portrayals of Wundt and Titchener in introductory psychology texts: a content analysis. Teaching of Psychology, 27(2), 122-126.

Recebido em 13/02/2006 Aceito em 22/02/2006

Endereço para correspondência: Hugo Klappenbach. Mitre 1326 (5700) San Luis, Argentina. E-mail: hklappen@unsl.edu.ar 
